\title{
Robin Williams and the Long Twentieth Century of American Sociology ... or Back to the Future
}

\author{
Peter Bearman ${ }^{1}$
}

In this essay, I reflect on the ways elements of Robin M. Williams Jr.'s research agenda might be carried forth in a meaningful way to sociological studies of twenty-first-century phenomena - in particular identifying the ways in which the facts of human interaction, of human expectation, and of human influence shapes outcomes of significance for our present, our future, and, therefore, our past.

KEY WORDS: social change; social continuity; social history; social theory; sociological mechanisms; Robin M. Williams Jr.

Robin Williams and I did not go back a long way, though he was there from the beginning for me. As editor of Sociological Forum, he accepted the paper that would turn out to be my first publication. He broke the ice, tempering the haunting experience of having previous paper submissions returned with the comments like "this paper must have been written on a word processor, because the text comes from one paper and the tables another." I had long been thankful that Williams was my editor, but I hardly knew him. Or more to the point, I knew little about his work. Reading his last paper, "The Long Twentieth Century in American Sociology" (hereafter, LTC), charged with evaluating his thoughts about the future of sociology, and suggesting where I saw the most productive future paths for the discipline was quite an experience.

1 Department of Sociology, Columbia University, SIPA Building 814, Mailcode 3355, ISERP, 420 West 118th Street, New York, New York 10027; e-mail: psb17@columbia.edu. 
It led me down all sorts of paths and I concluded that I would have been a better sociologist if I had read more Williams much earlier. Williams, who worked for a long time, was way ahead of his time pretty much from the beginning.

On first glance, the long twentieth century motif appears to be a stretch. The practical problem is that this long century started in 1914 and whole bunches of people think that it ended sometime around 1968, or perhaps 1989. This would make the twenty-first century long, should we have a twenty-second, but the twentieth distinctly short. This empirical concern notwithstanding, the "long twentieth century" is designed to bring to mind some of the other long centuries, for example, the long nineteenth century from the French Revolution to World War I, which is, not incidentally, the context for our discipline, or even the long sixteenth century, which ushered in the set of social institutions and ways of being and thinking we associate with modernity. Nothing so dramatic or important has happened in our long U.S. century of sociology, though. One looks forward to reading the LTC to discover that, indeed, some real epochal revolution was almost complete (as in the other long centuries) but it is not to be. The LTC is long in the same way that a Ken Burns documentary is long. It just goes on and on.

The relevant comparison is to the European sociologists of the long nineteenth century, all of whom had a theory of history - as equality, as struggle, as rationalization. These theories enabled an active engagement with the total empirical world, and so their sociology actively made the world. Contrast this fantastic scientific endeavor with our more domesticated ambitions today. We have pretty much chased theories of history out of the discipline. Whereas the founding fathers of the discipline had a theory of history, we have historical sociology. The same could be said for any of the other "sociologies." Perhaps it is simple enough to just observe, as Williams does, that the ASA now has 40 specialized sections, focusing on such "distinct phenomenon" as stratification, the family, religion, conflict, politics, history, and, of course, animal-human relations. In the LTC, we discover that Williams has mixed feelings about this development. He feels it is a disaster in the short term. He has hopes for the long term.

First, what we see in the short term is back-breaking work in the mines of observation and reportage. American sociology of the long twentieth century appears to Williams as a project in which people more often than not set out to describe the world, just as it is, or just as it was, just 
as it seems to people who are living in it. $^{2}$ This is what makes it feel so long, it is an endless exercise. It is also an exercise that gives rise to the peculiar situation described by Williams in the LTC in which we discover that the disciplinary problems of some distant year before we were born - but when he was already active, and perhaps even the President of the ASA - were exactly the same problems we have now, in 2008. The LTC in which Williams played a lead role for so long looks like a poorly directed horror movie, replete with multiple bad takes spaced out across generations.

Weirdly, this is what we have, and it is from this that Williams draws his vision for a possible future. It could be worse. We could become our cousins the economists armed with chain saws- "theories" and methodologies designed to turn the rich empirical world we occupy into an arid desert of anachronistic general laws. Maybe repetition is not so bad. After all, repetition does not occur because we don't learn from history, repetition occurs because we do learn from history. It is because history is congealed as the social and ideational structure in which we are embedded that we repeat ourselves. Repetition occurs because "social structures are not phantasmagoria" (Williams, 2006:18). The social structure of the discipline in a population of other disciplines focused on the tangible problems of human interaction in robust largely unchanging social structures gives rise to enduring problems. The enduring reality and salience of social structure is just one of those things that sociologists, and others, cannot really escape. And so many of our old problems haunt us now and likely will haunt us in the future. Of course, an epochal transformation of social structure will yield some new problems in the same way that the problems of the nineteenth century that gave rise to sociology were the product of the sixteenth-century soul searchers efforts to secure salvation. But to know now what world we are yet to be in requires a theory of history. And we do not have one. Williams and I agree that this is relative progress.

${ }^{2}$ Eric Leifer (1992) in an important paper published in Sociological Forum-under Williams' editorship, of course - asks us to imagine what our passive orientation to data would lead us to do should we happen to observe leaves falling from trees in the fall. There are observable disparities. Some leaves fall straight to the ground and stay there. Others swirl up into the air. Still others are carried in wide arcs over long distances. The rich description of different trajectories - the observable life courses of leaf falling - might invite the idea that one could explain the behavior of leaves by their innate differences or hidden preferences. And such a description based on such rich observation, with or without the added imputation of motive, would, of course, miss the main story-which is gravity. At the risk of being didactic, if you know about gravity you do not bother to observe the trajectories of leaves. In the same way, having a theory of history, for example, frees you from observation of data related to potholes on the road to the future. 
The puzzle for Williams, then, is: How do we get some traction without descending into mere observation and description (and thereby becoming historians or journalists) or embracing models so abstracted from context as to have no tangible sociological context (and thereby becoming economists)? Sociologists are drawn to change. That is peculiar, first, because change is far less common an experience than continuity and, second, because much of the change we report is of the same significance as the change that occurs when one zaps remotely from one TV station to another. But this was not Williams' project. His project was to make sense of the continuity of the social world. In this regard, his focus is consistent with the Parsonian functionalism from which he descended. In the LTC, to anticipate the next step, Williams suggested that traction on the highway of progress comes from identifying robust mechanisms that operate similarly across widely diverse contexts.

$\mathrm{He}$ gets to this point indirectly. In the LTC, Williams co-opts the imagery of Mills and connects his biography to larger social dynamics. The idea is that age gives him the liberty to do this, but that is nonsense and Williams knows we will come to that conclusion. Throughout our short twentieth century, Williams - who was always a sociologist and who never left Cornell - was where the action was: war, the Cold War, racial conflict, social movements, and so on. Here is an inventory of the major events of the time (as an aside, one of the oddities of the 1970s, as with our current decade, was a fascination with inventories, and even Williams was drawn in). What Williams saw when he worked in all these actionfilled contexts was not change but continuity. As Williams travels through some of his favorite times and places, we discover that each picaresque journey (down the narrative river) turns out to be the same trip. Sometime in the 1950s or so, Williams discovered some core mechanisms and he continued to find them, over and over again.

In the LTC, Williams seems to imply that if we just find important things to engage in and study, we, too, can find mechanisms. He suggests that we follow his lead, working on "targets of opportunity." These targets of opportunity are analogous to what Merton (1987) would call "strategic research sites." The implicit message of the LTC is that sociological progress arises from research engagement with these targets of opportunity, by which Williams and Merton meant important social contexts whose operation reveals core sociological mechanisms. ${ }^{3}$ I think this is not exactly fair. It is not as if important social contexts reveal mechanisms willy-nilly on their own. Maybe for Merton and Williams they did,

3 Just to be clear, engagement does not mean having opinions about important matters of the day, or being active in a professional association that passes resolutions in support of one opinion or another supposedly relevant to those important matters. 
but the rest of us need a trick. Williams had a trick for digging up mechanisms that we might well emulate. Finding himself in Context "A," he looked to see whether something about a mechanism identified in Context "B" was relevant. Williams was able to deny observations arising from the context he observed by adopting the standpoint of another "context." This is, of course, what a theory of history did for Tocqueville, Weber, and Marx, although here the goal is different: to identify mechanisms, by which I mean action- (and interaction-)based explanations of social outcomes at the middle range. ${ }^{4}$ That seems more modest, but it need not be. This is a project central to the discipline; it was, in my mind, Williams' project and it led him to mechanisms. Mechanisms are absolutely twentyfirst century, and so Williams was ahead of his time.

Thus it is fair to say that Williams discovered mechanisms at the middle range and from this believed we have the capacity to break through the endless description of things and achieve real cumulative knowledge. His explicit advice notwithstanding, for Williams, mechanisms are revealed only by active analogical theorizing (à la Vaughan, 2004), that is, the discovery of mechanisms is not possible if one adopts a passive - observational - orientation to the field. It follows that theory is the only tool that we have at our disposal with which to actively engage and shape the world. About this I believe most of us would agree. ${ }^{5}$ It is no accident, then, that the contributions of Merton and Williams were contributions to theory and that both held deeply pragmatic views on method, recommending that one use whatever seemed to work for the problem at hand. This seems like good advice.

Williams claims that "in its scientific aspects the field has achieved genuine and important intellectual advances" (Williams, 2006:21). In support of this claim, he offers an inventory of mechanisms and concepts that we have discovered and integrated into our research programs - relative deprivation, the Mathew principle, the principle of least interest, the dynamics of co-optation, structural holes, locals and cosmopolitans, weak states and weak ties, thresholds and emergence, and so on. Many of these discoveries have been executed into research programs in other fields more than in sociology. This is especially true of the most important revolution of our discipline - the network revolution-which has led to lasting changes in our understanding of the dynamics of complex human and

${ }^{4}$ For quite different reasons, as Craig Calhoun noted in his remarks in honor of Merton's career, this was also the strategy that Merton adopted, mainly to work around the institutional demands of the BASR.

${ }^{5}$ We might also note that Williams encountered mechanisms that were subsequently discovered. But discovery priority is less important in our discipline than in the harder sciences. And this is how it ought to be, since we should care about the sociological significance of discovery, which is really about capacity to execute discoveries into research programs. 
nonhuman social arrangements. All these achievements are achievements of theory, not method. As Williams notes throughout the LTC, there were always intense pressures for methodological purity in the discipline. There is nothing wrong with thinking about method as simply something to think with. The "methods wars" are not going to provide a solution to the presumed ills of the discipline in this present any more than they did in any of the innumerable presents of Williams' long career. If one believes that the discipline is sick, then method may appear to be the cure. But I do not think that the discipline is any sicker than it was, say, in 1908. That may not sound like progress, but continuity is nothing to sneeze at. It is, as Williams' work suggests, a pretty complex achievement.

So what about the future? Williams ends the LTC with a host of possibilities. The most compelling for him is the re-(re)discovery of the four classic problems of the long sixteenth century: the problem of order, the tragedy of the commons, the problem of collective action, and the problem of consensus (2006:19). Yikes - should we say: "Roll over Beethoven, tell Tchaikovsky the news"? These were problems for the early moderns and they are problems for us still. He does not precisely say so, but we know now that Parsons's rediscovery didn't stick because it was saddled with too much baggage to yield anything remotely like a usable research program. So, stripped of all the mumbo-jumbo, this is one possibility - and a pretty good one.

So what about the future? Williams cares about the future so he can rescue the past. For those of us just mining away, looking for that one regularity that can make sense of our projects in the here and now, this is not precisely our concern. It seems reasonable to suppose, though, that the discipline will be significantly strengthened by developments in other sciences. Nothing, for example, will provide a stronger foundation for the one profound sociological insight that we have-that social structures are not phantasmagorical and that making sense of social action rests on understanding the context in which social actors are embedded - than the continued "discovery" of genetic "determinants" of social behavior. If nothing else, this revolution might finally free us from the causality goblin, and let us get on with the much more challenging and much more rewarding activity of identifying the ways the facts of human interaction, of human expectation, and of human influence shape outcomes of significance for our present, our future, and, therefore, our past.

\section{REFERENCES}

Leifer, Eric. 1992. "Denying the Data: Learning from the Accomplished Sciences," Sociological Forum 7: 2: 283-299. 
Merton, Robert K. 1987. "Three Fragments from a Sociologist's Notebooks: Establishing the Phenomenon, Specified Ignorance, and Strategic Research Materials," Annual Review of Sociology 13: 1-28.

Vaughan, Diane. 2004. "Theorizing Disaster: Analogy, Historical Ethnography, and the Challenger Accident," Ethnography 5: 3: 313-345.

Williams, Robin M. Jr. 2006. "The Long Twentieth Century in American Sociology: A Semi-Autobiographical Survey," Annual Review of Sociology 32: 1-23. 